\title{
Intracranial dural arteriovenous fistula with perimedullary drainage treated by endovascular embolization
}

\section{Fístula arteriovenosa dural intracraniana com drenagem perimedular tratada por embolização via endovascular}

Lucas Giansante Abud1,2, Thiago Giansante Abud ${ }^{1,3}$, Guilherme Seizem Nakiri',4, Rodolfo Mendes Queiroz', Daniel Giansante Abud ${ }^{4}$

A 66-year-old woman presenting progressive tetraparesis during the past month. Magnetic resonance (MR) showed nonspecific abnormalities in the cervical spinal cord (Figure 1), which could be related to demyelination, neoplasia or inflammation ${ }^{1}$. However, these findings, in concomitance with extensive dilated perimedullary vessels, suggested myelopathy secondary to dural arteriovenous fistula (DAVF).
Digital angiography identified a Cognard type V intracranial DAVF (Figure 2). After prompt endovascular treatment (Figure 3), complete remission of symptoms was obtained.

Despite its intracranial location, type V DAVF presents, by definition, perimedullary venous drainage, which leads to venous congestion, and, consequently, intramedullary edema, progressive myelopathy and chronic hypoxia ${ }^{1,2,3}$.
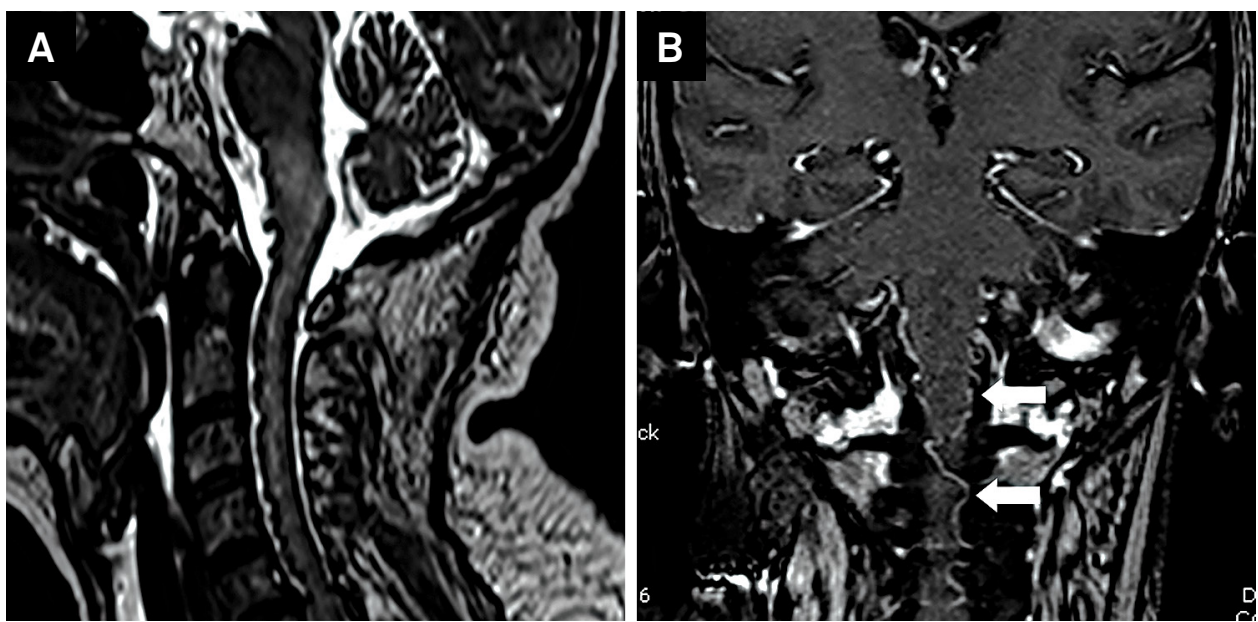

Figure 1. (A) Sagittal T2-weighted MRI of the cervical spine showing enlargement and signal change of spinal cord and bulb, characterizing myelopathy due to venous congestion. We can also see images of flow artifacts corresponding to enlarged perimedullary veins. (B) Coronal T1-weighted MRI after contrast injection showing venous ectasia around the bulb and spinal (white arrows).

\footnotetext{
1'Documenta, Hospital São Francisco, Departamento de Neurorradiologia, Ribeirao Preto SP, Brazil;

${ }^{2}$ Universidade de São Paulo, Faculdade de Medicina de Ribeirão Preto, Divisão de Neurorradiologia Diagnóstica, Ribeirao Preto SP, Brazil;

${ }^{3}$ Hospital Albert Einstein, Neurorradiologia Intervencionista, Sao Paulo SP, Brazil;

${ }^{4}$ Universidade de São Paulo, Faculdade de Medicina de Ribeirão Preto, Divisão de Neurorradiologia Intervencionista, Ribeirao Preto SP, Brazil. Correspondence: Lucas Giansante Abud; Rua Olavo Bilac, 839; 14020-020 Ribeirão Preto SP, Brasil; E-mail: abud.lucas@gmail.com Conflict of interest: There is no conflict of interest to declare.

Received 27 June 2015; Received in final form 18 August 2015; Accepted 11 September 2015.
} 

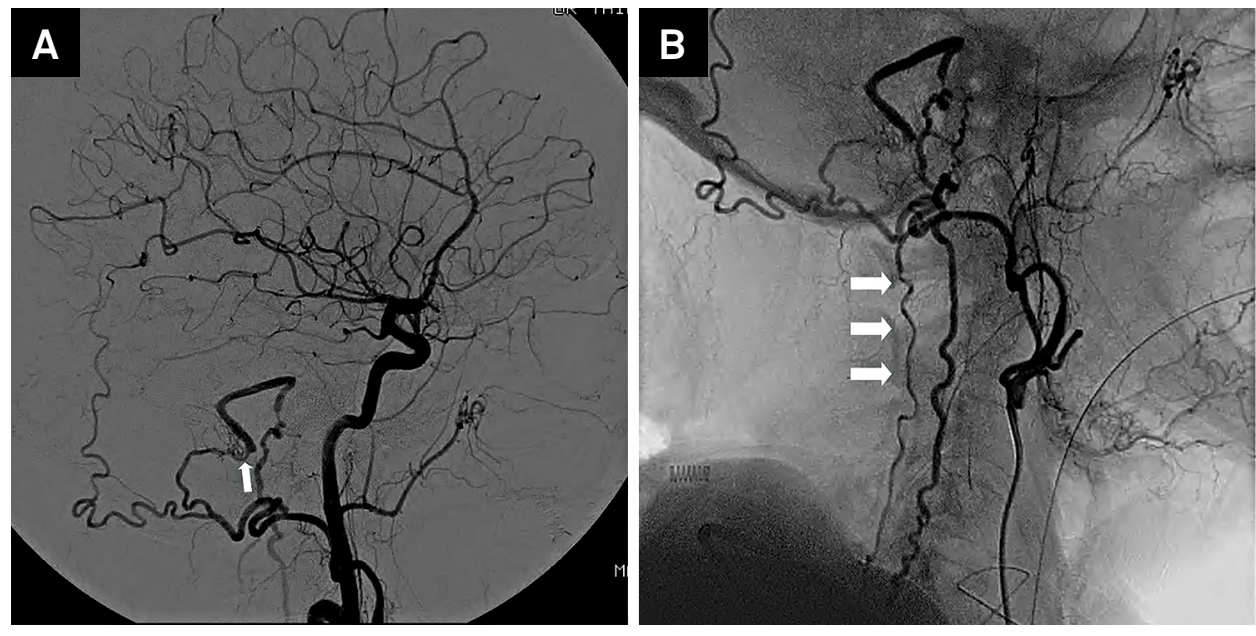

Figure 2. Digital angiography showing right sigmoid sinus DAVF (Cognard classification type V) being fed by transosseous branches of the right occipital artery (A) (white arrows), with cortical venous drainage through ectatic and tortuous perimedullary veins (B) (white arrows).
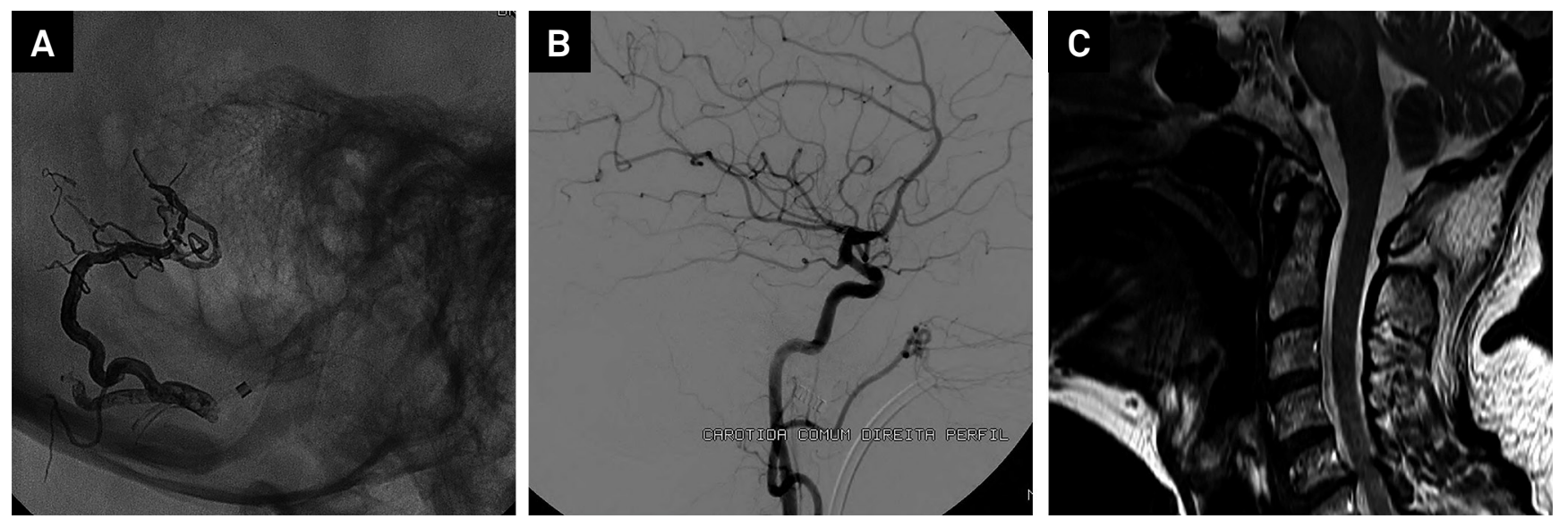

Figure 3. (A) and (B) Digital angiography after endovascular embolization with Onyx (Medtronic) showing resolution of the fistula. (C) Sagittal T2-weighted MRI of the cervical spine, at 3 months after treatment, demonstrating no evidence of cervical myelopathy or dilated vascular structures, with complete regression of the intramedullary edema.

\section{References}

1. Ernst RJ, Gaskill-Shipley M, Tomsick TA, Hall LC, Tew JM Jr, Yeh HS. Cervical myelopathy associated with intracranial dural arteriovenous fistula: MR findings before and after treatment. AJNR Am J Neuroradiol. 1997;18(7):1330-4.

2. Cognard C, Gobin YP, Pierot L, Bailly AL, Houdart E, Casasco et al. Cerebral dural arteriovenous fistulas: clinical and angiographic correlation with a revised classification of venous drainage. Radiology. 1995;194(3):671-80. doi:10.1148/radiology.194.3.7862961

3. Abud TG, Nguyen A, Saint-Maurice JP, Abud DG, Bresson D, Chiumarulo L, Enesi E, Houdart E. The use of Onyx in different types of intracranial dural arteriovenous fistula. AJNR Am J Neuroradiol. 2011;32(11):2185-91. doi:10.3174/ajnr.A2702 